Volume 1 -No. 27

\title{
Fault Diagnosis in Analog Integrated Circuits Using Artificial Neural Networks
}

\author{
A.Rathinam \\ SRM University
}

\author{
R.Srinivasa Raghavan \\ SRM University
}

\author{
R.Venkatraman \\ SRM University
}

\begin{abstract}
One of the most important tasks in design and manufacturing of integrated circuits is the testing phase. Distinguishing between faulty and fault free ICs is a difficult task Therefore, simulations are being done for different circuits to identify fault free and faulty circuits. Analog circuits like Low pass filter, High pass filter, Band pass filter, Band reject filter, State variable filter, Tow Thomas Biquadratic filter etc. The parameters measured are the variations in node voltages \& DC supply current. These parameters are specifically chosen for extracting the data, because of their ability to improve the efficiency of ANN.
\end{abstract}

The full text of the article is not available in the cache. Kindly refer the IJCA digital library at www.ijcaonline.org for the complete article. In case, you face problems while downloading the full-text, please send a mail to editor at editor@ijcaonline.org 